\title{
The coordination nanosheet (CONASH)
}

\author{
Ryota Sakamoto a,b,", Kenji Takada ${ }^{a}$, Xinsen Sun ${ }^{a}$, Tigmansu Pal ${ }^{a}$, Takamasa Tsukamoto ${ }^{\text {a }}$, Eunice \\ Jia Han Phua ${ }^{\mathrm{a}}$, Amalia Rapakousiou ${ }^{\mathrm{a}}$, Ken Hoshiko ${ }^{\mathrm{a}}$, Hiroshi Nishihara, ${ }^{\mathrm{a}, \mathrm{c},{ }^{*}}$ \\ ${ }^{a}$ Department of Chemistry, Graduate School of Science, The University of Tokyo, 7-3-1, Hongo, \\ Bunkyo-ku, Tokyo 113-0033, Japan \\ ${ }^{b}$ JST-PRESTO, 4-1-8 Honcho, Kawaguchi, Saitama 332-0012, Japan \\ ' JST-CREST, 4-1-8 Honcho, Kawaguchi, Saitama 332-0012, Japan
}

\section{Contents}

1. Introduction

2. CONASHs fabricated by dry processes

2.1 Metal-organic coordination networks

2.2 Other systems

3. CONASHs fabricated by wet processes

3.1 Ordered alignment of a sulfide molecule on a $\mathrm{Hg}$ surface

3.2 Surface metal-organic frameworks

3.3 Metal complex nanosheet

4. CONASHs as nanomaterials

4.1 Electrochromic bis(terpyridine)metal complex nanosheet

4.2 Conductive bis(dithiolene)metal complex nanosheet

4.3 Photofunctional bis(dipyrrinato)zinc(II) complex nanosheet

5. Conclusions 
Acknowledgments

References

Abstract: This review presents recent progress relating to metal-complex two-dimensional polymers, coordination nanosheets (CONASHs), an emerging class of material. Section 2 summarizes CONASHs fabricated by dry processes, such as organic molecular beam epitaxy and electron beam heating evaporation under ultra-high vacuum conditions. Section 3 describes CONASHs fabricated by wet processes, such as liquid/liquid and gas/liquid interfacial reactions. Section 4 describes the potential applications of CONASHs in nanomaterial science.

\section{Introduction}

Nanosheets are two-dimensional polymers with nanoscale thicknesses, the best known of which is graphene. Graphene has various unique, useful properties, such as giant and balanced carrier mobilities, large light absorptivities, efficient spin injection, large thermal conductivity, and high mechanical strength. These characteristics have applications in electronics [1], photonics [2], spintronics [3], capacitors, batteries, solar cells [4], and filler materials [5]. The outstanding properties of graphene have prompted research into analogues such as silicene [6], germanene [7], stanene, [8] and phosphorene [9]. Recently, a series of transition metal dichalcogenide (TMD) nanosheets has been also reported [10]. Other examples of nanosheets include metal oxides [11], metal hydroxides, [12] boron nitrides [13], and clay nanosheets [14]. These nanosheets all originate from bulk layered crystalline mother materials, and are classified as top-down nanosheets.

In contrast, bottom-up nanosheets are fabricated directly from atomic, ionic, or molecular components. Although the concept was proposed nearly a century ago, only recent progress in synthetic and analytical techniques has allowed bottom-up fabrication [15]. A significant advantage 
of bottom-up fabrication over top-down is that the composition and structure of the sheet can be controlled.

In this review, we summarize recent progress in coordination nanosheets (CONASHs), which are two-dimensional polymers based on coordination compounds. In Section 2, we describe CONASHs fabricated by dry processes, and in Section 3, we discuss those obtained by wet processes. The use of CONASHs as nanomaterials is detailed in Section 4.

\section{CONASHs fabricated by dry processes}

\subsection{Metal-organic coordination networks}

The carboxylate-metal coordination bond is the most important chemical bond in metalorganic frameworks (MOFs) [16] and porous coordination polymers (PCPs) [17]. A balance between bond strength and reversibility is useful in forming superstructures. Lin, Barth, and Kern first used the carboxylate-metal coordination bond to create a two-dimensional polymer structure in the vacuum phase (Fig. 1) [18a]. The carboxylate ligand, 1,2,4-benzenetricarboxylic acid (trimellitic acid; TMLA) (Scheme 1a), and Fe were co-deposited on a $\mathrm{Cu}(100)$ flat substrate in an ultra-high vacuum (UHV) chamber. TMLA was deposited by organic molecular beam epitaxy (OMBE), whereas the Fe source was evaporated by electron beam heating. The $\mathrm{Cu}(100)$ substrate was heated at $400 \mathrm{~K}$, so that the adsorbates were mobile on the surface to allow them to form networks. This method led to polymorphism; however, scanning tunneling microscopy (STM) showed that some of the structures contained two-dimensional nanosheets (Fig. 1). The TMLA precursor layer did not achieve monolayer saturation coverage, which left space for the formation of open network structures.

Fig. 2c,d shows a DFT-optimized structure of a two-dimensional network consisting of terephthalic acid (TPA) (Scheme 1b) and two Fe atoms reported by Seitsonen and Barth [18b]. The two Fe centers are coordinated by four TPA molecules. Two molecules adopt an $\eta^{2}$ coordination 
mode, and the other two molecules adopt a $\mu$ coordination mode. The bite angle is $117.3^{\circ}$ for the $\eta^{2}$-TPA ligands and $124.5^{\circ}$ for the $\mu$-TPA ligands, causing a slight bend in the molecular backbone so that it sits above the plane defined by the Fe atoms. The Fe-Fe spacing is $4.4 \AA$. The STM image at quasi-atomic resolution (Fig. 2a) was consistent with the simulated image (Fig. 2b).

There are several other related works $[18 \mathrm{c}-\mathrm{h}]$, including details of fullerene uptake in the network pores $[18 \mathrm{c}]$. 


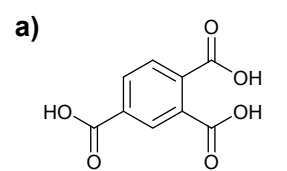

1,2,4-benzenetricarboxylic acid (TMLA)

e)

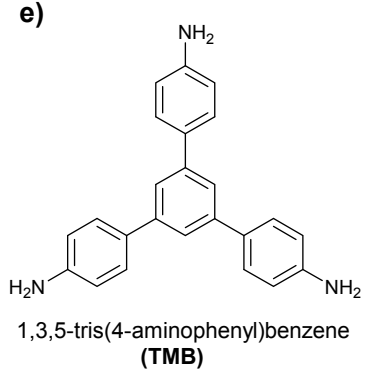

b)
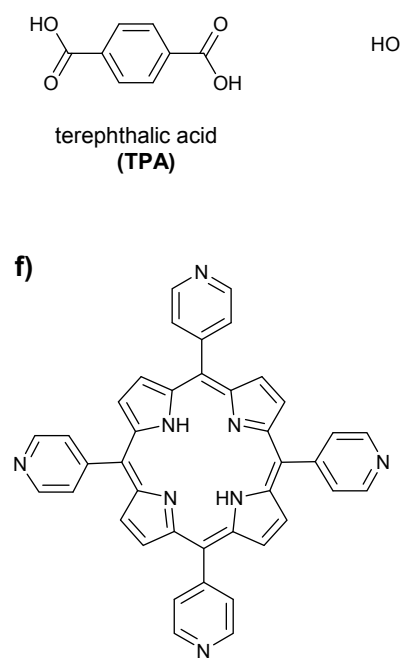

5,10,15,20-tetra(4-pyridyl)porphyrin c)

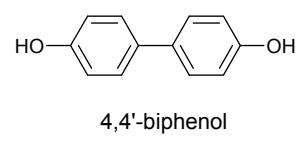

d)

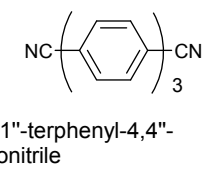

g)

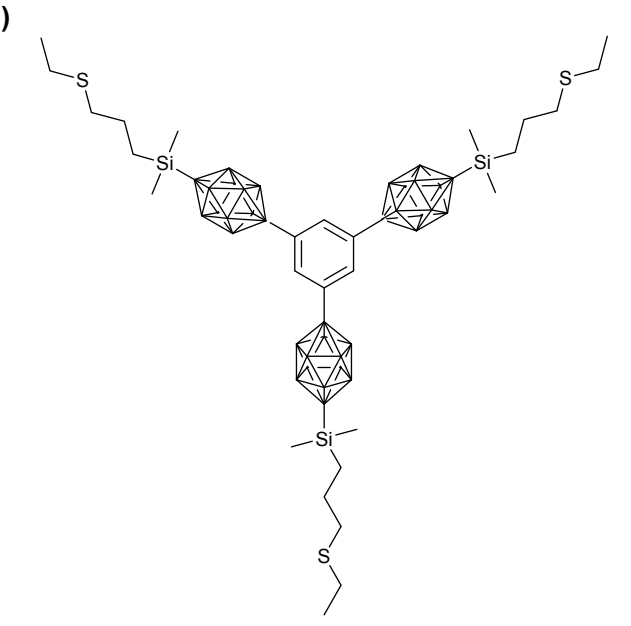

h)

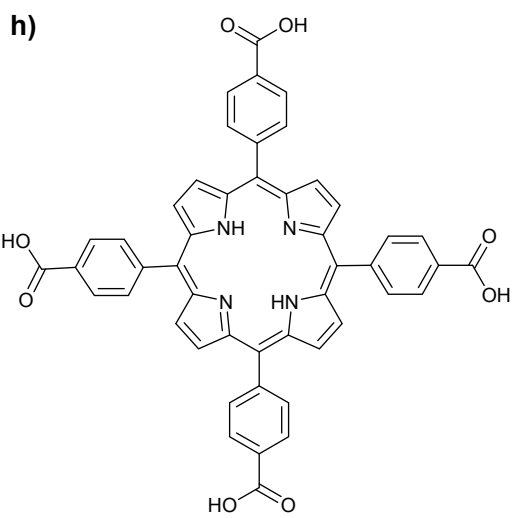

5,10,15,20-tetrakis(4-carboxyphenyl)porphyrin $\left(\mathbf{H}_{\mathbf{2}} \mathbf{T C P P}\right)$

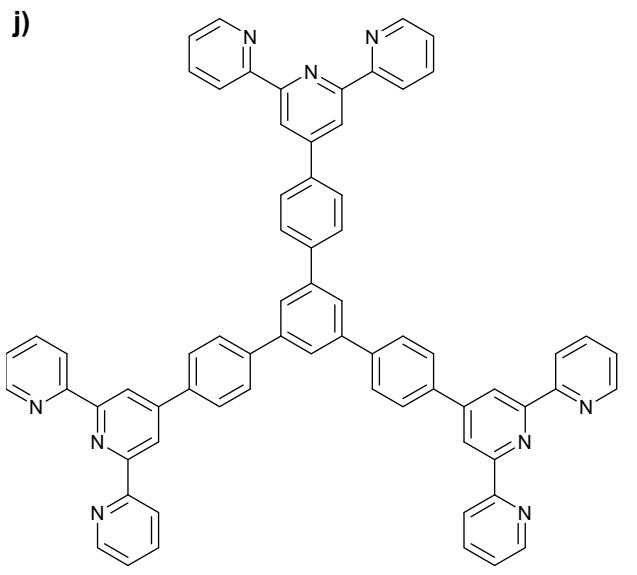

three-way terpyridine ligand 3

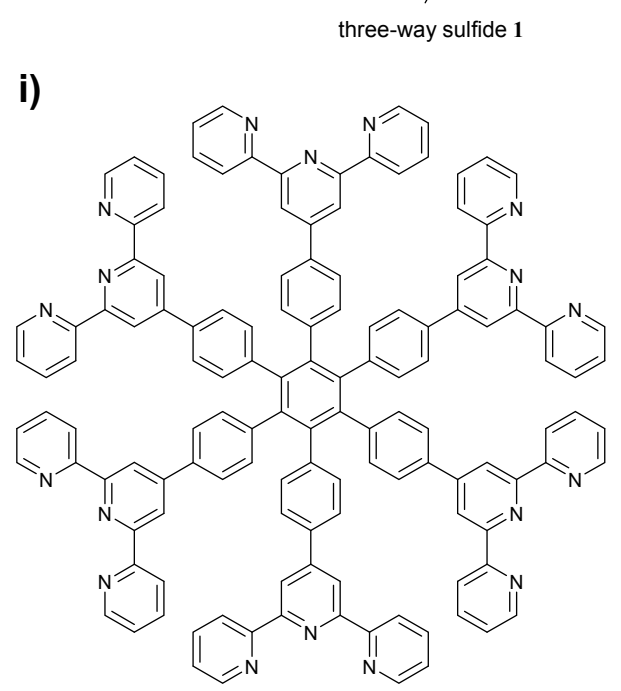

six-way terpyridine ligand 2

l)

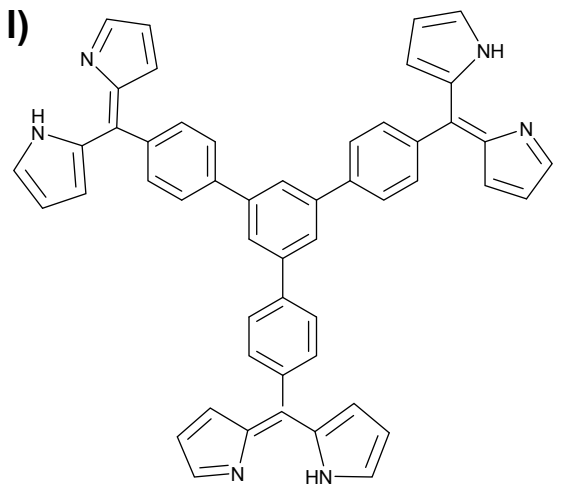

three-way dipyrrin ligand $\mathbf{5}$

Scheme 1. Schematic illustrations of organic ligand molecules involved in this review. 

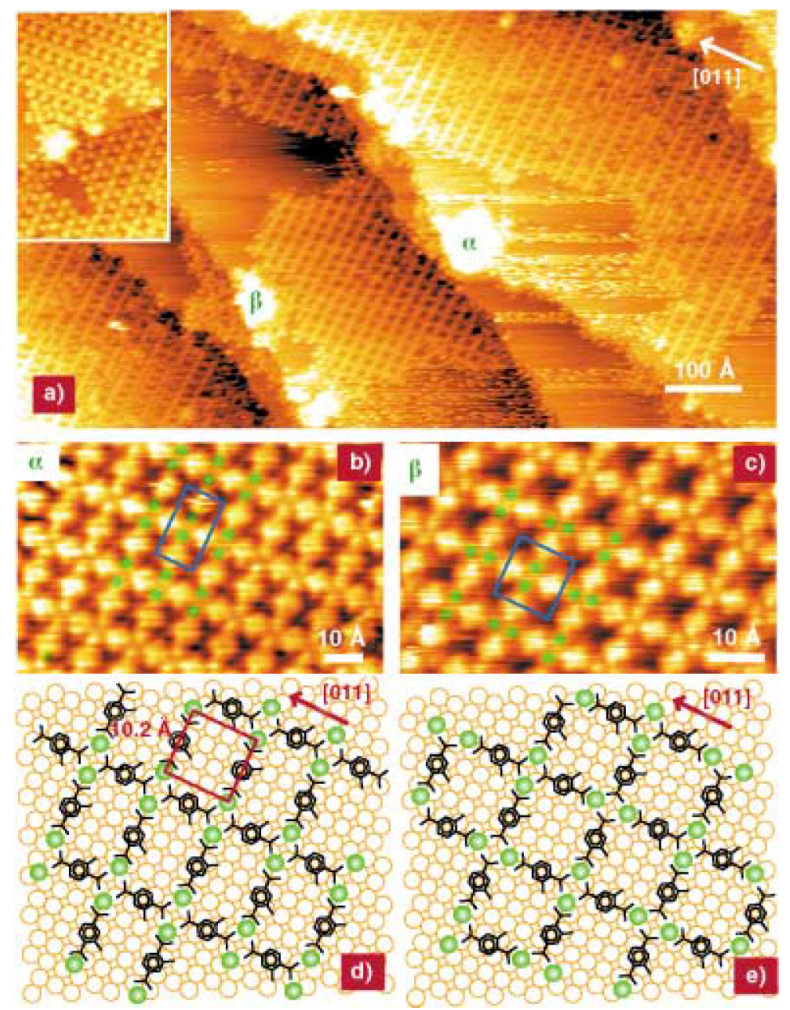

Fig. 1. The first two-dimensional network comprising the carboxylate ligand, TMLA, and Fe atoms. (a) STM topography showing two types of regularly ordered networks designated as the $\alpha$ and $\beta$ phases. The inset shows both the $90^{\circ}$ rotational domains of the $\alpha$ phase. $(b, c)$ High-resolution STM images in which the arrangement of Fe and TMLA in both the $\alpha$ and $\beta$ phases is resolved. The $\alpha$ phase has a rectangular unit cell and the $\beta$ phase has a square unit cell. $(\mathrm{d}, \mathrm{e})$ Tentative models that identify the $\alpha$ and $\beta$ phases. Although both phases have the same stoichiometry and contain Fe atoms with identical coordination environments, their geometrical arrangement is different. Reproduced with permission from Ref. [18a]. Copyright 2003 Wiley-VCH Verlag GmbH \& Co. KGaA. 


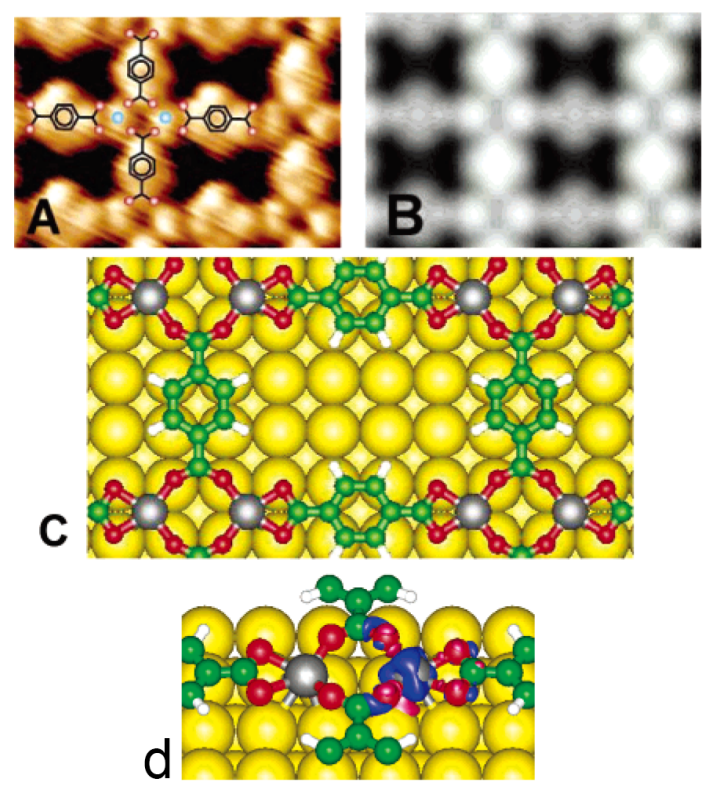

Fig. 2. Fully reticulated nanoporous Fe-diterephthalate grid assembled on a $\mathrm{Cu}(100)$ substrate. (a) Constant current mode STM image showing the R-isomer comprising a $(6 \times 4)$ unit cell (image size $40 \AA \times 30 \AA)$. The arrangement of the TPA backbone indicates that a molecule is engaged in either two bidentate or four unidentate carboxylate bonds to the Fe-Fe centers (two blue spheres). (b) STM image simulation showing the contours of the constant local density of states at the sample Fermi level derived from the DFT model of the optimized structural arrangement in the model in (c). (d) Perspective view of the Fe-Fe unit. The Fe charge rearrangement contour levels indicated on the right, drawn with respect to a removed $\mathrm{Fe}$ atom, are $\pm 0.004 \mathrm{e}^{-} / \AA^{3}$. Purple indicates increased electron density and blue indicates decreased electron density. Carboxylate moieties and Fe centers lie in almost the same plane $(\Delta \mathrm{z} \approx 0.2 \AA)$, with the Fe centers displaced from the four-fold hollow sites, resulting in a lateral Fe-Fe spacing of $4.4 \AA$. Adapted with permission from Ref. [18b]. Copyright 2006 American Chemical Society.

\subsection{Other systems}

The pioneering work by Lin and coworkers paved the way to several variations of surfacesupported two-dimensional coordination polymers [19-21]. Lin and coworkers reported that 4,4'biphenol (Scheme 1c) and 1,4':4',1"-terphenyl-4,4"-dicarbonitrile (Scheme 1d) functioned as bridging ligands, and formed two-dimensional nanosheets with Fe and Co, respectively, on Au(100) and $\operatorname{Ag}(111)$ by using a method similar to the combination of OMBE and electron beam heating (Fig. 3) [19a]. The hydroxy and cyano groups acted as coordination sites, producing trigonal-planar coordination spheres (Fig. 3c). Schlickum and coworkers fabricated a large-scale, neat, two- 
dimensional structure using 1,4':4',1"-terphenyl-4,4"-dicarbonitrile and Co (Fig. 4) [19b]. Bartels reported that the adatom gas of a $\mathrm{Cu}(111)$ surface could also serve as a metal source for cyano bridging ligands [19c], requiring no metal evaporation, simplifying the fabrication process. Similar results were reported by Lackinger [19d].

Lackinger also found that a thiol ligand, 1,3,5-tris(4-mercaptophenyl)benzene (TMB) (Scheme 1e), may form two-dimensional coordination structures [20]. Under UHV conditions, TMB was deposited thermally on a $\mathrm{Cu}(111)$ surface at $145{ }^{\circ} \mathrm{C}$, forming an ordered horizontal monolayer, with the thiol group deprotonated. After thermal annealing at $160-200{ }^{\circ} \mathrm{C}$, the monolayer was transformed into various polymorphs, one of which featured a kagome lattice (Fig. 5). DFT calculations showed the two-dimensional structure to contain a characteristic coordination motif, where twin $\mathrm{Cu}$ atoms are ligated by two thiol ligands (Fig. 5c).

A pyridyl functional group can also be used to construct two-dimensional coordination structures under UHV conditions. 5,10,15,20-Tetra(4-pyridyl)porphyrin (Scheme 1f) was deposited on an $\mathrm{Au}(111)$ surface at $650 \mathrm{~K}$ by physical vapor deposition (PVD), and $\mathrm{Cu}$ metal was evaporated by using an electron-beam evaporator [21]. Thermal annealing at $450 \mathrm{~K}$ generated the twodimensional structure (Fig. 6). A Cu atom was taken up into the porphyrinic core to form a divalent Cu porphyrin motif, which was observed by X-ray photoelectron spectroscopy (XPS). Additionally, according to STM and DFT calculations, a $\mathrm{Cu}(0)$ atom was captured by two peripheral pyridyl groups, producing a chessboard lattice. 


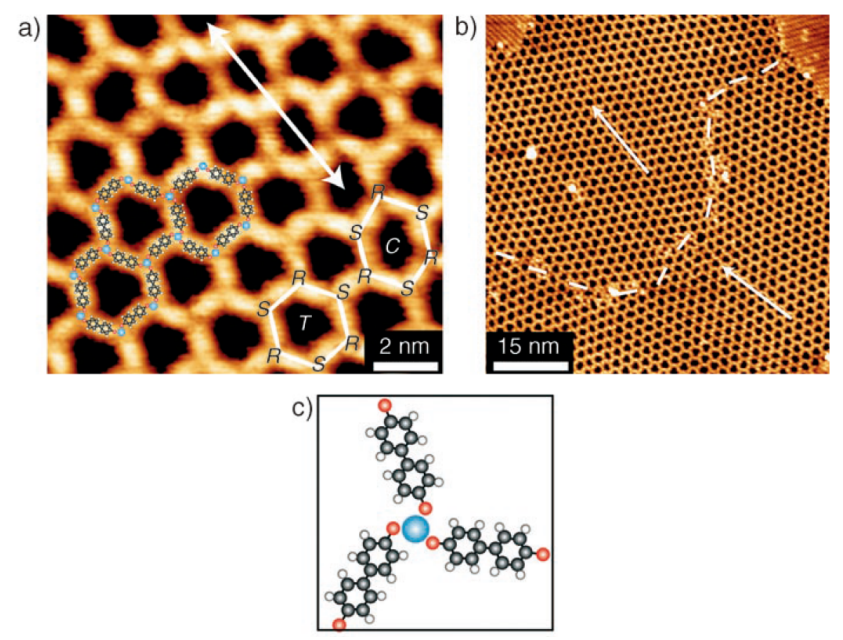

Fig. 3. STM topographs displaying the hexagonal Fe-biphenolate network assembled on $\operatorname{Ag}(111)$. (a) High-resolution STM image. A tentative model is superimposed on the data. The T-type and Ctype hexagons are highlighted by white frames. The double arrow indicates a ribbon of hexagons only consisting of $\mathrm{C}$ hexagons. $\mathrm{R}$ and $\mathrm{S}$ denote the clockwise and counterclockwise folding, respectively, of the three biphenolate ligands, one around each Fe center. (b) Overview of the two domains separated by a domain boundary (dashed line). The white arrows indicate the domain orientations. The image was taken at a tunnel current of $0.1 \mathrm{nA}$ and a bias voltage of $0.5 \mathrm{~V}$. (c) Model of the threefold binding of the nodal Fe(biphenolate) $)_{3}$ motif. Adapted with permission from Ref. [19a]. Copyright 2007 Wiley-VCH Verlag GmbH \& Co. KGaA.

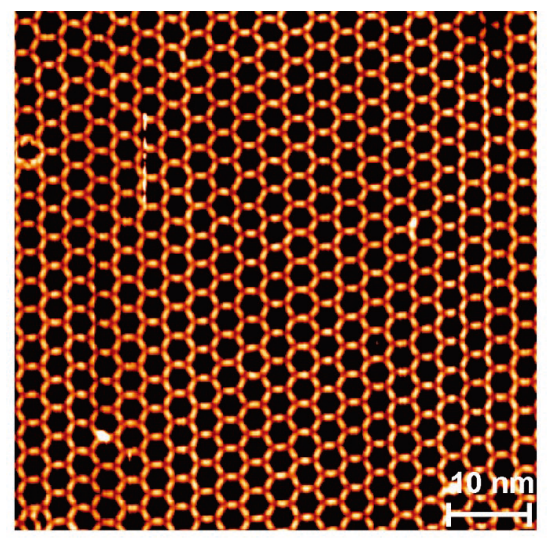

Fig. 4. Overview STM topographic image of a large-scale metal-organic network formed by $1,4^{\prime} ; 4^{\prime}, 1^{\prime \prime}$-terphenyl-4,4"-dicarbonitrile and Co. Adapted with permission from Ref. [19b]. Copyright 2007 American Chemical Society. 

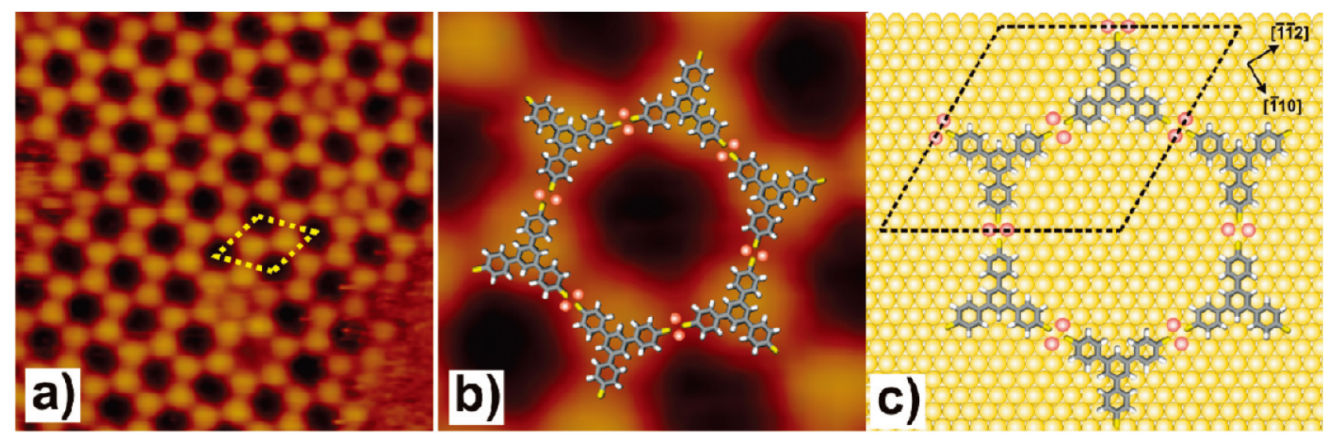

Fig. 5. (a) STM topographic of the honeycomb structure with the unit cell indicated $\left(U_{\mathrm{T}}=-1.0 \mathrm{~V}\right.$, $\left.I_{\mathrm{T}}=67 \mathrm{pA}, 24 \mathrm{~nm} \times 24 \mathrm{~nm}, a=b=3.4 \mathrm{~nm}, \gamma=120^{\circ}\right)$ and (b) close-up $(6.5 \mathrm{~nm} \times 6.5 \mathrm{~nm})$ of the honeycomb structure with a molecular model. (c) Tentative model of the honeycomb structure including the substrate. The hexagonal unit cell is indicated by black dashed lines. Reproduced with permission from Ref. [20]. Copyright 2011 American Chemical Society.

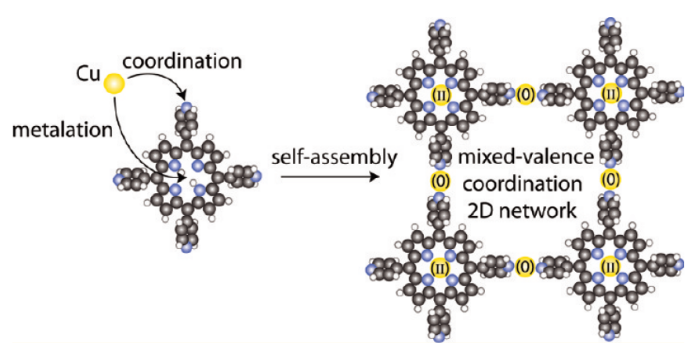

Fig. 6. Schematic illustration of a chessboard lattice comprising $\mathrm{Cu}$ (II)-inserted 5,10,15,20-tetra(4pyridyl)porphyrin and $\mathrm{Cu}$ atoms. Reproduced with permission from Ref. [21]. Copyright 2012 American Chemical Society.

\section{CONASHs fabricated by wet processes}

\subsection{Ordered alignment of a sulfide molecule on an $\mathrm{Hg}$ surface}

Varaksa, Magnera, and Michl found that three-way sulfide 1 (Scheme 1g) underwent twodimensional ordering on a $\mathrm{Hg}$ surface in an electrochemical Langmuir-Blodgett trough (Fig. 7) [22a]. According to electrochemical measurements and Langmuir adsorption isotherms in $0.1 \mathrm{M}$ $\mathrm{LiClO}_{4} /$ acetonitrile, no adsorption occurred at electrode potentials more negative than $-0.85 \mathrm{~V}$ (vs. 
$\mathrm{Ag} / \mathrm{AgCl}$ in $1 \mathrm{M} \mathrm{LiCl}$ ), whereas physisorption was observed at potentials between -0.85 and $0 \mathrm{~V}$. At more positive potentials, anodic dissolution of $\mathrm{Hg}$ occurred with the assistance of $\mathbf{1}$ adsorbed on the $\mathrm{Hg}$ surface, forming an organized surface layer. $\mathrm{Hg}^{2+}$ was reduced again at $-0.10 \mathrm{~V}$, although the surface layer remained metastable until $-0.85 \mathrm{~V}$. Although the two-dimensional network structure was not characterized in detail, theoretical calculations indicated that sulfide $\mathbf{1}$ formed a hexagonal network upon coordination with $\mathrm{Hg}^{2+}$ or $\mathrm{Hg}_{2}{ }^{2+}$.

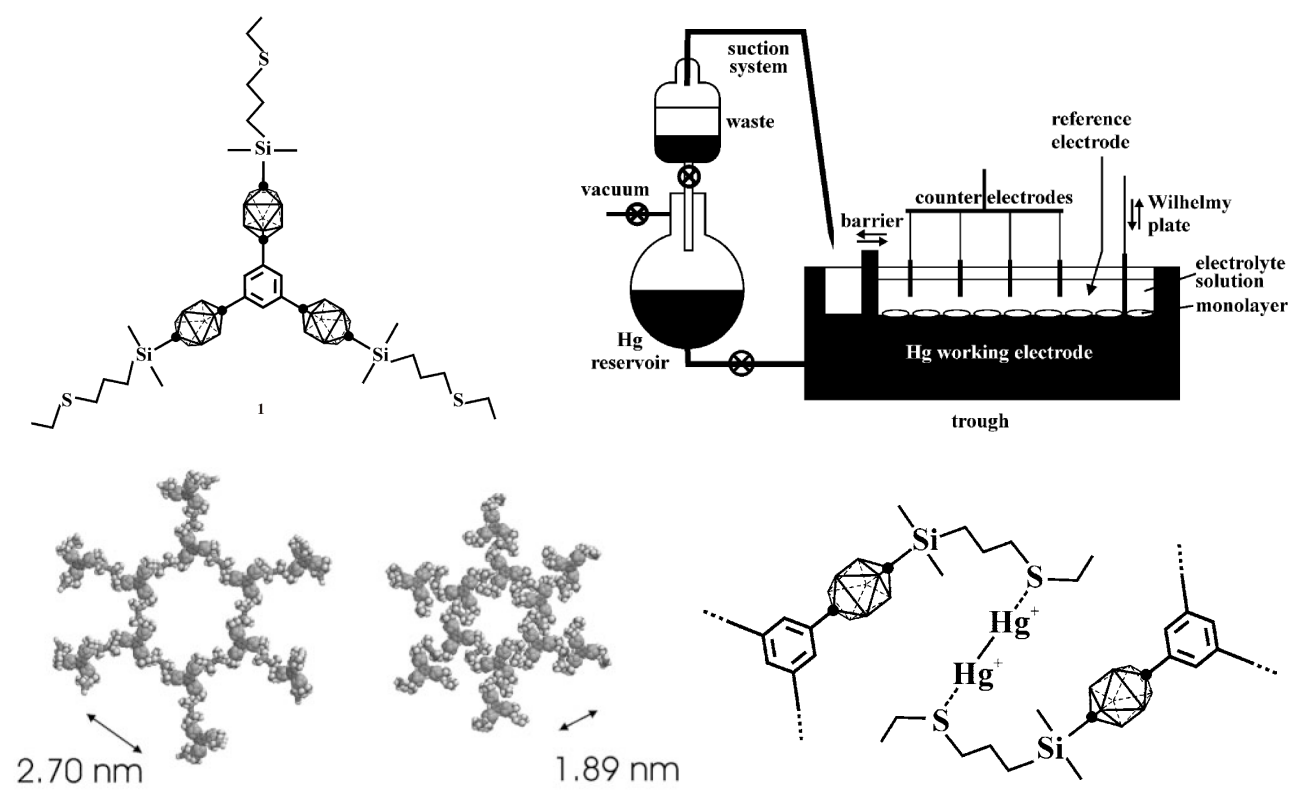

Fig. 7. (a) Molecular structure of sulfide 1. The dots in the carborane cages indicate carbon atoms, and the other vertices indicate BH groups. (b) Schematic of the electrochemical Langmuir-Blodgett trough. (c) Two AM1-optimized structures of the proposed hexagonal network bound through $\mathrm{Hg}^{2+}$. (d) Most probable structure of a hexagon edge in the proposed hexagonal network of $\mathbf{1}$ bound through $\mathrm{Hg}_{2}{ }^{2+}$. Reproduced with permission from Ref. [22a]. Copyright 2002 National Academy of Sciences.

\subsection{Surface metal-organic frameworks}

Makiura and Kitagawa accomplished an air/liquid interfacial synthesis of single-layer MOFs, and their stepwise accumulation on a flat substrate (Fig. 8) [23]. They used 5,10,15,20-tetrakis(4carboxyphenyl)porphyrin ( $\left.\mathbf{H}_{2} \mathbf{T C P P}\right)$ (Scheme $1 \mathrm{~h}$ ) as a carboxylate ligand to create a two- 
dimensional MOF (NAFS-2) [23b]. The synthetic procedure is distinctive, and uses a method similar to the Langmuir-Schäfer technique. An aqueous $\mathrm{CuCl}_{2}$ solution was used as the subphase, where $\mathrm{Cu}^{2+}$ serves as a metal linker. The subphase $\mathbf{H}_{2}$ TCPP migrated to the surface of the toluene/ethanol, forming a network at the air/liquid interface by complexation. The nanosheet floating on the interface was then transferred onto a flat substrate. NAFS-2 was stacked layer-bylayer by repeating the synthesis and deposition, and the accumulation was characterized quantitatively by UV/vis and IR spectroscopy. Additionally, the authors analyzed the stacked sample by X-ray diffraction (XRD) with a synchrotron, which showed that the desired crystalline structure had formed (Fig. 8b,c). The horizontal orientation of the NAFS-2 film was obtained by grazing-incidence XRD (GIXRD) analysis. The average crystalline domain size was estimated to be $20 \mathrm{~nm}$ from the full width at half maximum of the GIXRD peak by using Scherrer's equation and atomic force microscopy (AFM).

In addition, MOF nanosheets can be obtained by other methods, such as exfoliation of bulk crystals [24] and surface-anchored MOF techniques [25]. 

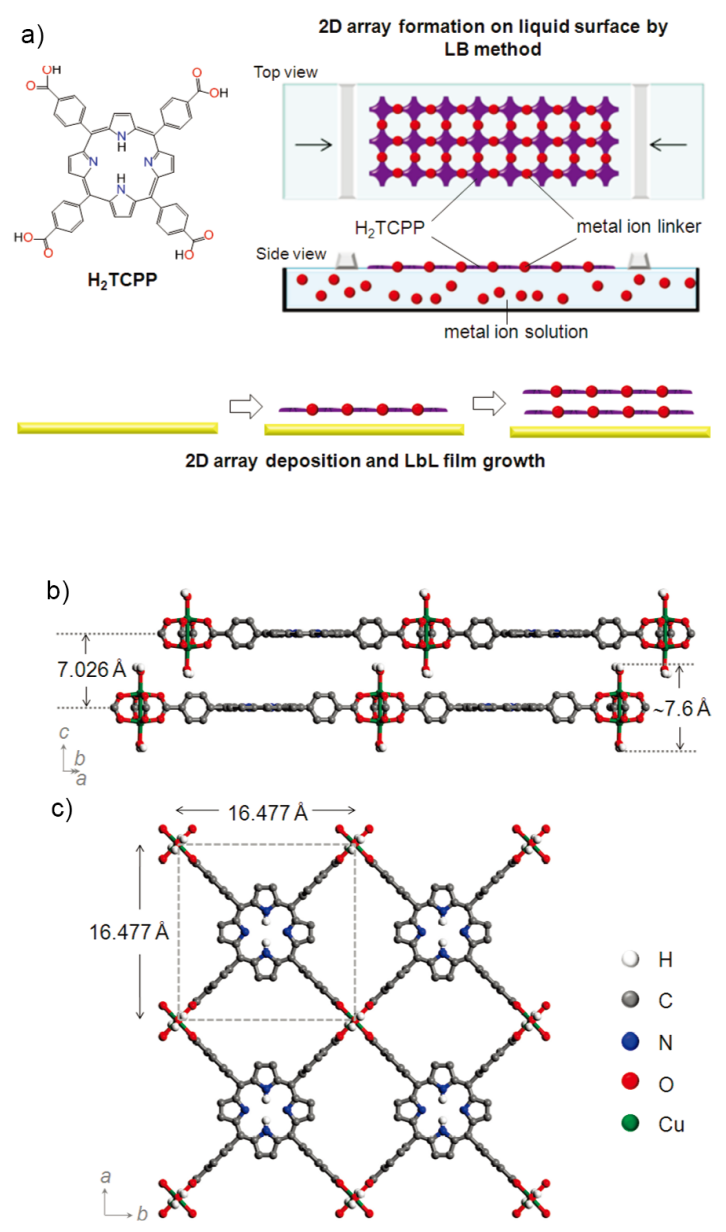

Fig. 8. (a) Schematic illustration of the representative assembly processes of NAFS-2 involved in the combined Langmuir-Schäfer technique. (b) Schematic diagrams of the proposed crystalline structure of NAFS-2. H atoms are shown in white, $\mathrm{C}$ in gray, $\mathrm{N}$ in blue, $\mathrm{O}$ in red, and $\mathrm{Cu}^{2+}$ in green. Some $\mathrm{H}$ atoms have been omitted for clarity. Reproduced with permission from Ref. [23b]. Copyright 2011 American Chemical Society.

\subsection{Metal complex nanosheet}

CONASHs have been developed beyond conventional MOF chemistry. Sakamoto and Schlüter reported two-dimensional polymers featuring the bis(terpyridine)metal complex motif (Fig. 9) [26]. Terpyridine is a useful ligand for fabricating supramolecules [27] and one-dimensional coordination polymers [28] because of its robust, facile complexation of various metal ions. Sixway terpyridine ligand 2 (Scheme 1i) formed a nanosheet structure in combination with $\mathrm{Fe}^{2+}$ by 
using a method similar to that introduced in Section 3.2. However, the terpyridine ligand was preoriented at the air/water interface under compression. The sheet structure was verified by AFM, optical microscopy, and TEM (Fig. 9b-e). The advantage is that the domain sizes of these nanosheets are large. Large single or few-layer sheets $(>500 \mu \mathrm{m} \times 500 \mu \mathrm{m})$ were fabricated, which possessed sufficient mechanical strength to be freestanding on holey substrates. Schlüter also reported that the $\mathrm{Zn}^{2+}$-centered nanosheet could be transmetalated with $\mathrm{Fe}^{2+}, \mathrm{Co}^{2+}$, and $\mathrm{Pb}^{2+}[26 \mathrm{~b}]$.

Sakamoto and Nishihara synthesized bis(dithiolene)metal complex nanosheets [29] and bis(dipyrrinato)metal complex nanosheets [30]. These CONASHs, which are potential nanomaterials, are introduced in the following section. 

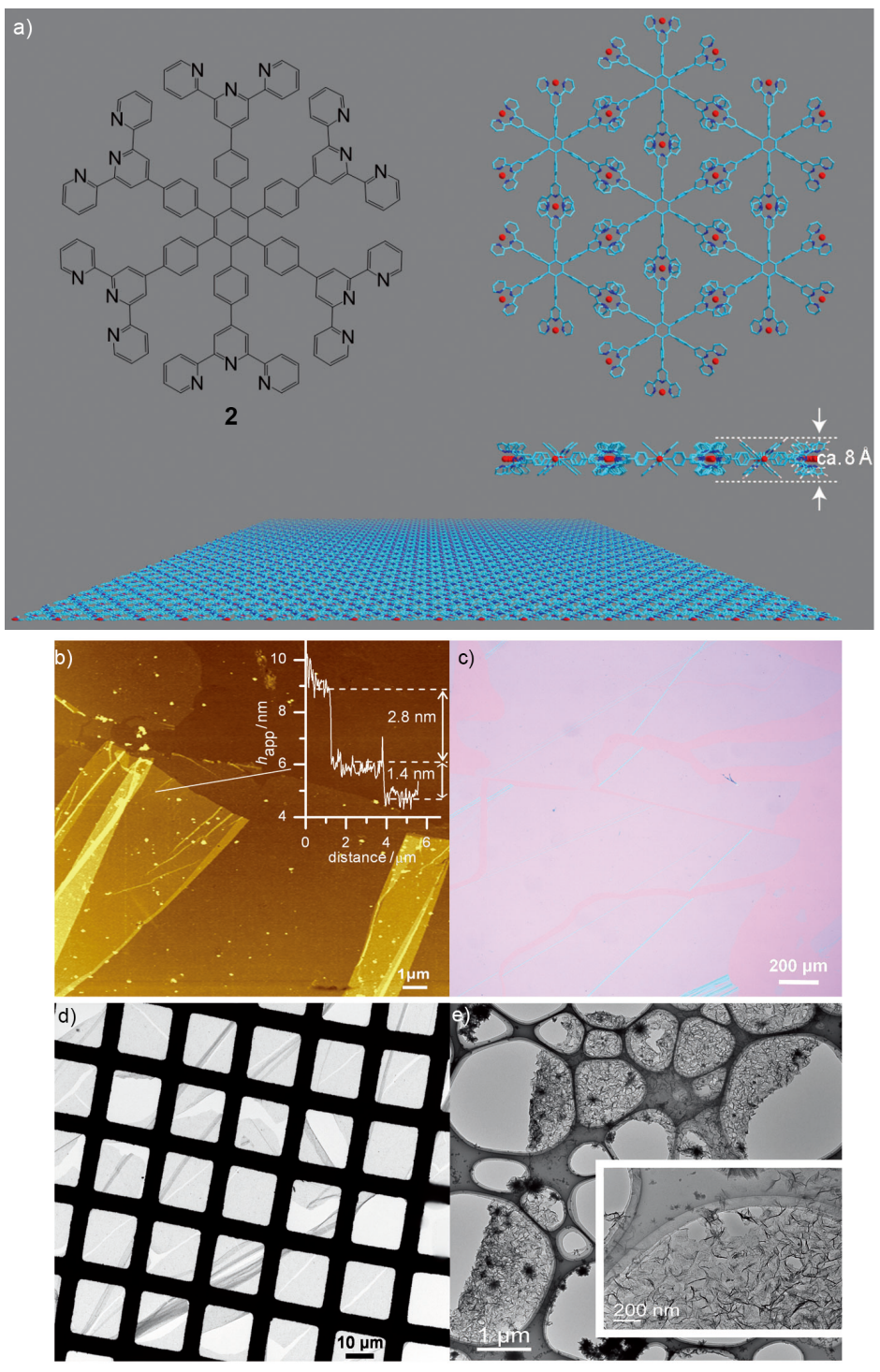

Fig. 9. (a) Chemical structure of monomer 2 and a small- and large-scale representation of an idealized two-dimensional network obtained from 2 through metal-ion complexation between terpyridine units of adjacent monomers (metal ion, red; $\mathrm{C}$, turquoise; $\mathrm{N}$, blue). The central image shows a cross-sectional view for estimating the layer thickness $(0.8 \mathrm{~nm}$, without counter ions). (b) Tapping-mode AFM image with a height profile measured along the white line in (a). (c) Optical microscope image after vertical transfer onto $300 \mathrm{~nm} \mathrm{SiO} / 2 \mathrm{Si}$ and annealing for $2 \mathrm{~min}$ at approximately $80^{\circ} \mathrm{C}$. (d) TEM image after horizontal transfer from the top onto a $\mathrm{Cu}$ grid with 20 $\mu \mathrm{m} \times 20 \mu \mathrm{m}$ holes. (e) TEM images at two different magnifications after horizontal transfer from the subphase onto a holey carbon grid. Adapted with permission from Ref. [26a]. Copyright 2011 Wiley-VCH Verlag GmbH \& Co. KGaA. 


\section{CONASHs as nanomaterials}

\subsection{Electrochromic bis(terpyridine)metal complex nanosheet}

Nishihara and Sakamoto reported several types of functional CONASHs [29-31]. For example, a solid-state electrochromic device containing bis(terpyridine)metal complex nanosheets (Fig. 9) as active layers has been fabricated (Fig. 10) [31], exploiting the rapid, robust redox reactions of the bis(terpyridine)metal complex motif [28]. A three-way terpyridine ligand 3 (Scheme 1j) was used to synthesize $\mathrm{Fe}^{2+}$ and $\mathrm{Co}^{2+}$ nanosheets (3-Fe and 3-Co) with thicknesses suitable for electrochromic materials. 3-Fe or 3-Co was synthesized at a liquid/liquid interface from a dichloromethane solution of $\mathbf{3}$ layered on an aqueous phase containing $\mathrm{Fe}\left(\mathrm{BF}_{4}\right)_{2}$ or $\mathrm{CoCl}_{2}$, respectively (Fig. 10a). The nanosheet thickness was controlled by the reaction conditions, such as the concentration of the metal source and the reaction time, affording, for example, thin (10 $\mathrm{nm})$ and thick (200 nm) 3-Fe. A significant advantage of the liquid/liquid synthesis is that it can provide large $(\sim 10 \mathrm{~cm})$ nanosheets with no defects, which is particularly important for practical applications. The thick nanosheet was deposited on an indium-tin oxide (ITO) electrode, which was then installed in a two-electrode solid-state electrochromic device (Fig. 10b). Divalent 3-Fe was originally deep purple; however, applying a positive voltage $(+3.0 \mathrm{~V})$ oxidized the Fe center from $\mathrm{Fe}^{2+}$ to $\mathrm{Fe}^{3+}$, turning it pale yellow (Fig. 10c). Applying a negative voltage $(-1.8 \mathrm{~V})$ reduced 3-Fe to the divalent state, changing it back to deep purple. The electrochromic change was robust and fast; the faradaic current response was completed in $0.35 \mathrm{~s}$, and negligible color fade-out was observed after 800 redox cycles using an organic electrolyte solution. Similarly, orange divalent 3-Co was converted reversibly to a purple $\mathrm{Co}^{+}$center (Fig. 10d). Finally, a dual electrochromic device was fabricated, where one ITO electrode was modified with 3-Fe in the shape of ' 0 ', and the other with 3-Co in the shape of ' 1 ' (Fig. 10e). Applying specific voltages showed ' 1 ' and ' 0 ' alternately (Fig. 10f). 


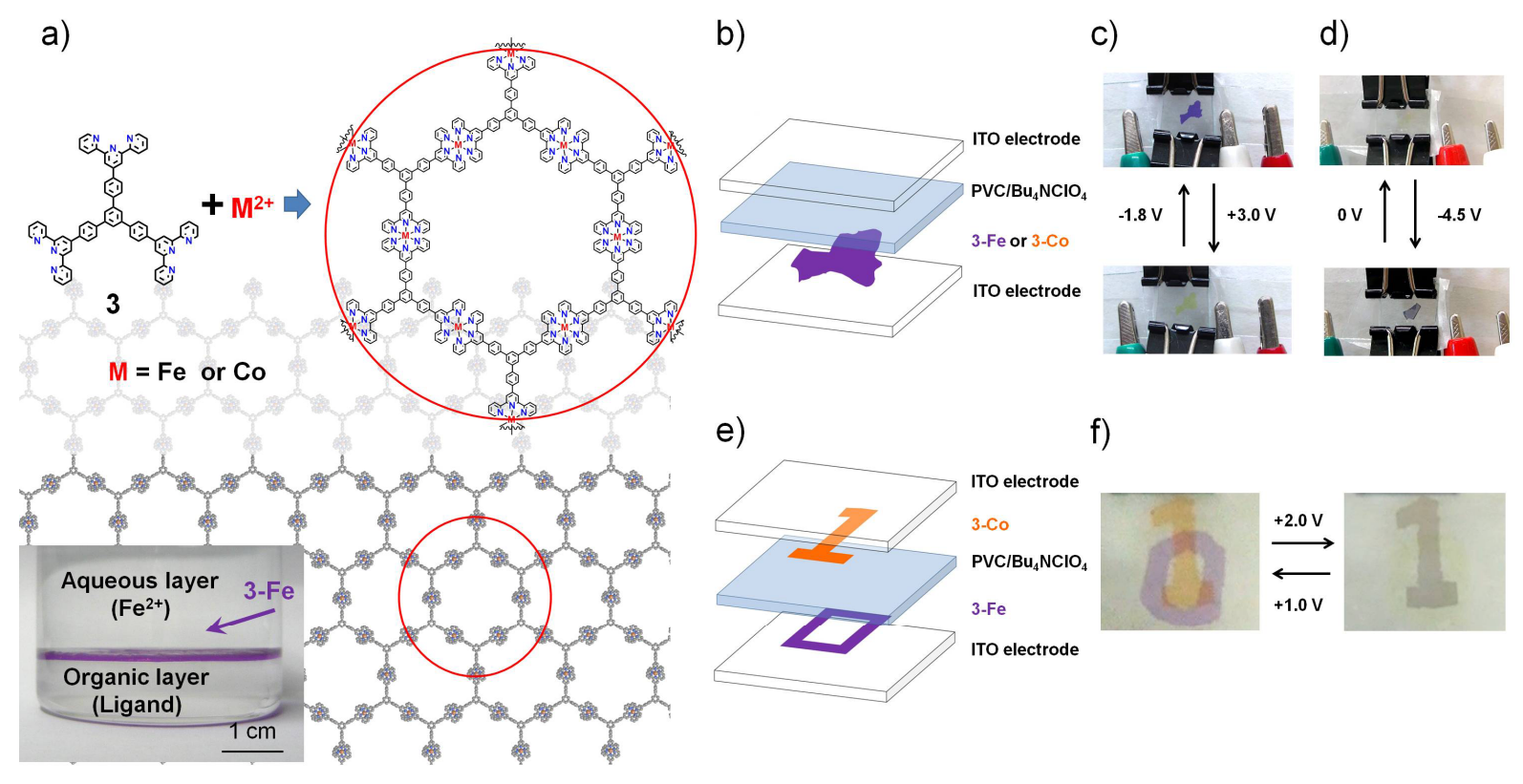

Fig. 10. (a) Structure of three-way terpyridine ligand 3 and bis(terpyridine)metal(II) complex nanosheets 3-Fe and 3-Co. The inset shows a photograph of the liquid/liquid interfacial synthesis. (b) Structure of an electrochromic device composed of 3-Fe or 3-Co. (c) Operation of the device with 3-Fe. (d) Operation of the device with 3-Co. (e) Structure of a dual-electrochromic device composed of 3-Fe and 3-Co. (f) Operation of the dual electrochromic device. Adapted with permission from Ref. [31]. Copyright 2015 American Chemical Society.

\subsection{Conductive bis(dithiolene)metal complex nanosheet}

CONASHs containing $\pi$-conjugated electronic structures are of particular interest due to their various potential useful properties, similar to graphene. However, this type of nanosheet has been difficult to fabricate. Nishihara and coworkers designed and synthesized a bis(dithiolene)nickel complex nanosheet (4-Ni; Fig. 11) [29]. The bis(dithiolene)metal complex motif contained two quasi-aromatic five-membered rings that showed good electronic communication [32]. They had previously reported trinuclear dithiolene metal complexes fused with a phenylene bridge, where valences were highly delocalized among the three dithiolene rings [33]. Based on the series of previous works, 4-Ni was expected to possess a $\pi$-conjugated structure (Fig. 11a). 4-Ni was synthesized from benzenehexathiol 2 (Scheme 1k) and nickel(II) acetate by a liquid/liquid interfacial synthesis (Fig. 10a) that afforded a multi-layer nanosheet with a thickness of 
$\sim 1 \mu \mathrm{m}$. A single-layer nanosheet was synthesized by a gas/liquid interfacial reaction (Fig. $8 \mathrm{a}$ ) that required no compression. The as-prepared nanosheet featured a mixed-valence state. The oxidation state of the nickel bis(dithiolene) unit was clearly observed in the S 2p XPS (Fig. 11b), and multilayer 4-Ni possessed a 63:37 ratio of units in the 0 and -1 oxidation states. The oxidation state could be tuned by chemical oxidation and reduction, producing monovalent states of 0 and -1 by using tris(4-bromophenyl)aminium hexachloroantimonate and 7,7,8,8-tetracyanoquinodimethane radical anion sodium salt, respectively. Fig. 11c shows a representative AFM image of the singlelayer nanosheet with a thickness of $0.6 \mathrm{~nm}$. The $\pi$-conjugated electronic structure was reflected in the high electrical conductivity. As-prepared and oxidized multi-layer 4-Ni (thickness: $1 \mu \mathrm{m}$ ) were subjected to the van der Pauw method under the control of scanning electron microscopy (SEM), giving electrical conductivities of $1.6 \times 10^{2}$ and $2.8 \mathrm{~S} \mathrm{~cm}^{-1}$ at $300 \mathrm{~K}$ (Fig. 11d-f). These values were high for coordination polymers and the conductivity could be tuned by the oxidation state.

Thus, 4-Ni could be used as an electronic material. Recently, Liu and coworkers proposed that the bis(dithiolene)nickel complex nanosheets including 4-Ni as a single-layer may be suitable as the first organic two-dimensional topological insulator (2D-TI) [34]. The TI is a new state of matter, with an insulating bulk part but metallic-phase edges (surfaces or sides). In addition, the metallic edge is spin-polarized and transmits a spin current. Thus, TIs are promising materials for electronics and spintronics. Various types of inorganic three-dimensional TIs (3D-TIs) have been reported recently, but two-dimensional TIs have been still rare. 


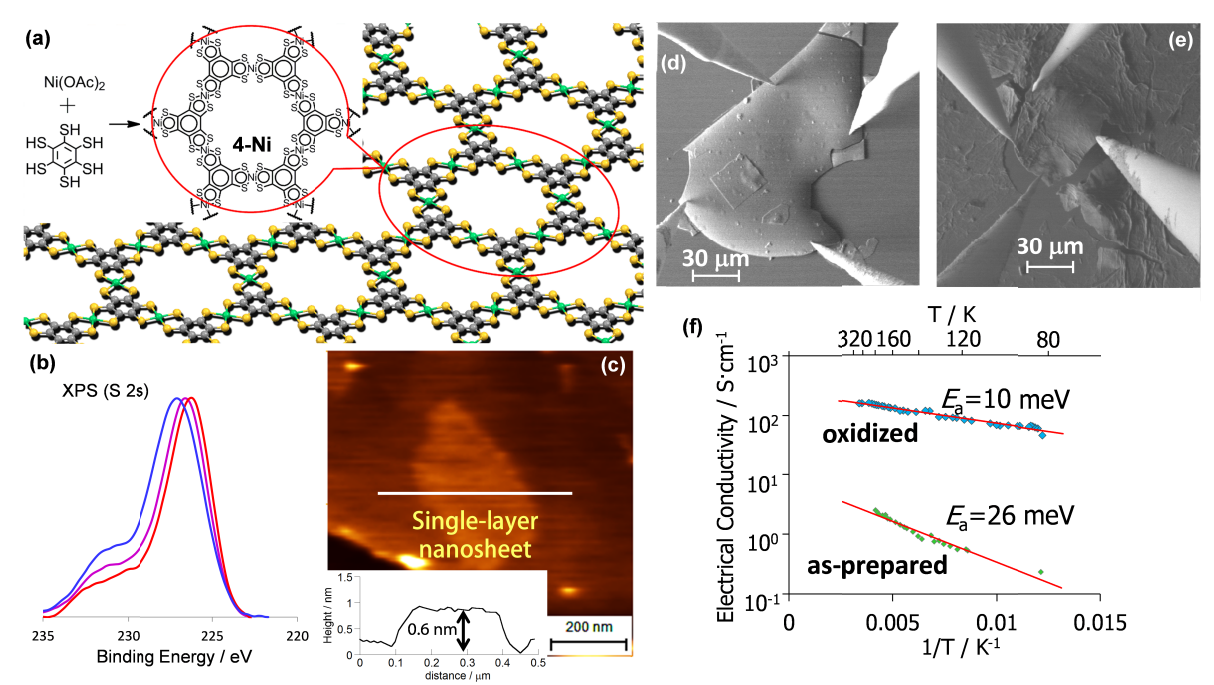

Fig. 11. (a) Chemical structures of the benzenehexathiol and bis(dipyrrinato)nickel(II) complex nanosheet 4-Ni. (b) XPS of multi-layer 4-Ni. Blue: oxidized form; purple: as-prepared form; red: reduced form. (c) AFM image of single-layer 4-Ni. (d,e) Electrical conductivity measurements for multi-layer 4-Ni using a four-probe method under the control of SEM. (d) Oxidized sample. (e) Asprepared sample. (f) Conductivity-temperature dependence. Adapted with permission from Ref. [29a,b]. Copyright 2013 and 2014 American Chemical Society.

\subsection{Photofunctional bis(dipyrrinato)zinc(II) complex nanosheet}

Bis(dipyrrinato)metal(II) and tris(dipyrrinato)metal(III) complexes show strong light absorption and fluorescence in the visible region [35]. Another distinctive characteristic is their spontaneous coordination, which is useful for fabricating supramolecules and coordination polymers [36]. By exploiting these properties, Sakamoto and Nishihara designed and synthesized photofunctional CONASH 5-Zn based on the bis(dipyrrinato)zinc(II) complex motif (Fig. 12a) [30]. $\mathbf{5 - Z n}$ is composed of a three-way dipyrrin ligand $\mathbf{5}$ (Scheme 11) and $\mathrm{Zn}^{2+}$ ions, and is synthesized by interfacial methods. Multi-layer $\mathbf{5 - Z n}$ was fabricated by a liquid/liquid interfacial reaction under ambient conditions, where a layer of aqueous $\mathrm{Zn}(\mathrm{OAc})_{2}$ reacted with a dichloromethane solution of 5 (Fig. 12b). The resultant multi-layer nanosheet was large and flat (Fig. 12b,f,g). The concentration of 5 controlled the thickness of multi-layer $\mathbf{5 - Z n}$ in the range of 6-800 nm, corresponding to 5-670 layers. On the other hand, the air/liquid interfacial reaction, where a dichloromethane solution of $\mathbf{5}$ was dropped gently onto the surface of aqueous $\mathrm{Zn}(\mathrm{OAc})_{2}$, produced single-layer 5-Zn (Fig. 12c). 
The resultant nanosheet with an atomic thickness was removed from the interface and deposited onto various substrates. A representative AFM image of single-layer 5-Zn transferred onto a hydrophobized $\mathrm{Si}(111)$ substrate is shown in Fig. $12 \mathrm{~h}$. The domain size reached $10 \mu \mathrm{m}$ on one side, which is large for bottom-up nanosheets. An AFM tip-scratch experiment confirmed that singlelayer $\mathbf{5 - Z n}$ was deposited (Fig. 12i,j). Scratching removed the nanosheet $\mathbf{5 - Z n}$, whereas the bare $\operatorname{Si}(111)$ substrate surface remained intact. Fig. $12 \mathrm{j}$ shows cross-section analysis for the step generated by the scratch, revealing that the nanosheet was $1.2 \mathrm{~nm}$ thick, which is consistent with the size of the bis(dipyrrinato)zinc(II) complex motif. Thus, 5-Zn formed a soft single-layer.

Sakamoto and Nishihara used $\mathbf{5 - Z n}$ in a photoelectric conversion system. Multi-layer $\mathbf{5 - Z n}$ was attached to a transparent, semiconductive $\mathrm{SnO}_{2}$ electrode, which was used as a photoanode. The decorated $\mathrm{SnO}_{2}$ electrode was installed in a photoelectric conversion cell filled with an acetonitrile electrolyte solution containing triethanolamine (TEOA) as a sacrificial electron donor. Fig. 12k displays a typical photocurrent response obtained upon irradiation with intermittent 500 $\mathrm{nm}$ green light, corresponding to the absorption maximum of 5-Zn (Fig. 121). A current response was acquired only when the light was on. In addition, the action spectrum was consistent with the ${ }^{1} \pi-\pi^{*}$ absorption band of 5-Zn (Fig. 121). These results indicate that the observed photocurrent was induced by the photoexcitation of $\mathbf{5 - Z n}$, resulting in the photocatalytic oxidation of TEOA. The highest quantum efficiency was $0.86 \%$, which was much higher than vales shown by reference systems fabricated with existing techniques from modified $\mathrm{SnO}_{2}$ photoanodes. One reference photoanode was an electrode to which a mononuclear bis(dipyrrinato)zinc(II) complex sensitizer was physisorbed. The other contained a mononuclear bis(dipyrrinato)zinc(II) complex chemisorbed through a carboxylate to the electrode. These two photoanodes showed poorer photoelectric conversion than the 5-Zn photoanode, with quantum efficiencies of $0.030 \%$ and $0.069 \%$ for the photoanodes containing the physisorbed and chemisorbed mononuclear complexes, respectively. The nanosheet structure of $\mathbf{5 - Z n}$ may provide the electrolyte and TEOA with enough space to move 
easily, and suppress the aggregation of the bis(dipyrrinato)zinc(II) complex units, protecting the photoexcited state from being quenched. These factors may enhance the photoelectric conversion of 5-Zn. The presence of nanopores or mesopores was deduced from the uptake of Rhodamine B pigment into multi-layer 5-Zn (Fig. 5e). Thus, 5-Zn is the first bottom-up nanosheet with photofunctionality.

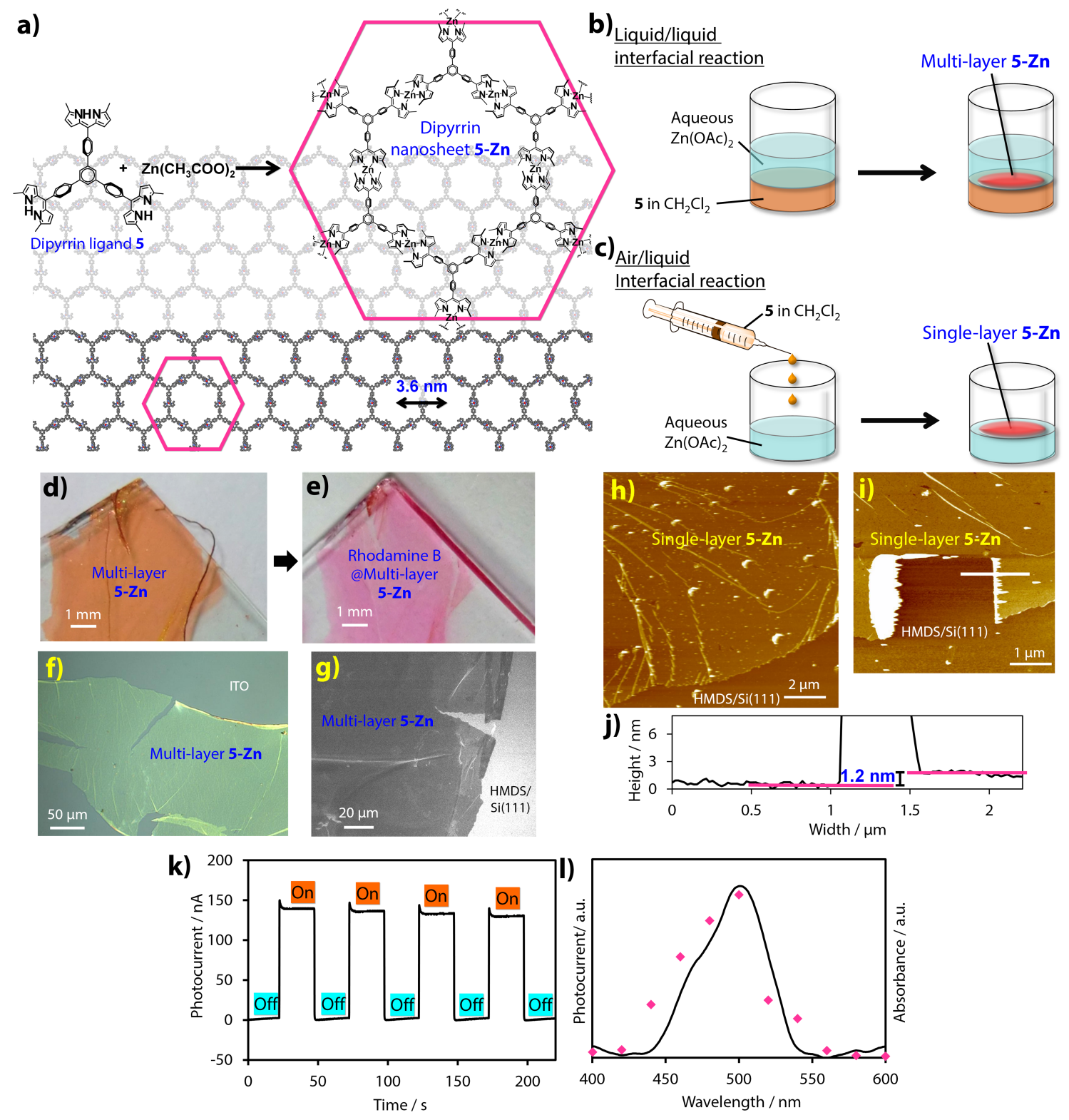


Fig. 12. (a) Chemical structures of three-way dipyrrin ligand 5 and bis(dipyrrinato)zinc(II) complex nanosheet 5-Zn. (b,c) Schematics of liquid/liquid and air/liquid interfacial syntheses. (d) Photograph of multi-layer 5-Zn transferred onto an ITO substrate. (e) Photograph of multi-layer 5Zn stained with Rhodamine B on an ITO substrate. (f) Optical microscope image of multi-layer 5Zn on an ITO substrate. (g) Field-emission SEM image of multi-layer 5-Zn on a 1,1,1,3,3,3hexamethyldisilazane-modified $\mathrm{Si}(111)$ [HMDS/Si(111)] substrate. (h) AFM height image of single-layer 5-Zn on HMDS/Si(111). (i,j) AFM height image of single-layer 5-Zn after scratching with the AFM tip, and cross-section analysis at one of the steps in the scratched region (white line in i). (k) Typical anodic current response upon irradiation of a working electrode $\left(\mathrm{SnO}_{2}\right.$ substrate modified with multi-layer 5-Zn) with intermittent $500 \mathrm{~nm}$ light in an acetonitrile electrolyte solution (0.1 M tetrabutylammonium perchlorate with 0.05 M TEOA) (1) Action spectrum for the photocurrent generation (magenta dots) and absorption spectrum of 5-Zn (black solid line). Adapted with permission from Ref. [30a]. Copyright 2015 Macmillan Publishers Limited.

\section{Conclusions}

This review surveys research on bottom-up CONASHs synthesized through the reaction of metal atoms or ions with organic bridging ligands. Top-down nanosheets obtained from lamellar 3D crystals, such as graphene and TMDs, are currently the focus of 2D-materials research. However, bottom-up nanosheets, such as CONASHs, are attracting increasing attention because of the wide variety and tunability of their chemical structures and physical/chemical properties. CONASHs can be, for example, synthesized readily by coordination reactions at gas/liquid and liquid/liquid interfaces. Dry processes using OMBE and electron beam heating evaporation under UHV conditions have also been developed. Most studies of CONASHs have described the formation of 2D crystalline structures, although some recent research has characterized the unique physical properties of CONASHs, such as electrochromism, metallic conductivity, and photoelectric conversion. These new discoveries should pave the way to rapid progress in the fundamental science and engineering of CONASHs and their practical applications.

\section{Acknowledgments}

The present article is chiefly supported by JST-PRESTO "Hyper-nano-space design toward Innovative Functionality" and JST-CREST "Development of Atomic or Molecular Two- 
Dimensional Functional Films and Creation of Fundamental Technologies for Their Applications". The present article is partly supported by Grants-in-Aid from MEXT of Japan (Nos. 26708005, 26107510, 26220801, 15H00862, 15K13654, areas 2406 [All Nippon Artificial Photosynthesis Project for Living Earth], 2506 [Science of Atomic Layers], and 2509 [Molecular Architectonics]). R.S. is grateful to Asahi Glass Foundation, Iketani Science and Technology Foundation, The MIKIYA Science and Technology Foundation, Yazaki Memorial Foundation for Science and Technology, Shorai Foundation for Science and Technology, The Hitachi Global Foundation, Kumagai Foundation for Science and Technology, Foundation for Interaction in Science \& Technology (FIST), The Foundation Advanced Technology Institute, Izumi Science and Technology Foundation, The Foundation for The Promotion of Ion Engineering, LIXIL JS Foundation, and THE IWATANI NAOJI FOUNDATION for financial supports. K.T., T.T., and E.J.H.P. thank a JSPS Postdoctoral Fellowship for young scientists. E.J.H.P. acknowledges Materials Education Program for the Future Leaders in Research, Industry, and Technology (MERIT). A.R. acknowledges a JSPS Postdoctoral Fellowship for Overseas Researchers. K.H. is grateful to Fostering program of human resources in chemistry conducted by Japan Chemical Industry Association.

[1] (a) A. K. Geim, K. S. Novoselov, Nat. Mater. 6 (2007) 183. (b) Y. M. Lin, C. Dimitrakopoulos, K. A. Jenkins, D. B. Farmer, H. Y. Chiu, A. Grill, P. Avouris, Science 327 (2010) 662. (c) K. S. Novoselov, A. K. Geim, S. V. Morozov, D. Jiang, Y. Zhang, S. V. Dubonos, I. V. Grigorieva, A. A. Firsov, Science 306 (2004) 666.

[2] F. Bonaccorso, Z. Sun, T. Hasan, A. C. Ferrari, Nat. Photon. 4 (2010) 611.

[3] (a) J. Maassen, W. Ji, H. Guo, Nano. Lett. 11 (2011) 151-155. (b) Y.-W. Son, M. L. Cohen, S. G. Louie, Nature 444 (2006) 347. 
[4] (a) X. Wang, L. Zhi, K. Muellen, Nano Lett. 8 (2008) 323. (b) C. Guo, H. Yang, Z Sheng, Z. Lu, Q. Song, C. Li, Angew. Chem. Int. Ed. 49 (2010) 3014.

[5] (a) K. M. F. Shahil, A. A. Balandin, Nano Lett. 12 (2012), 861-867. (b) V. Goyal, A. A. Balandin, Appl. Phys. Lett. 100 (2012) 073113. (c) G. Eda, M. Chhowalla, Nano Lett. 9 (2009) 814. (d) X. Huang, Z. Yin, S. Wu, X. Qi, Q. He, Q. Zhang, Q. Yan, F. Boey, H. Zhang, Small 7 (2011) 1876. (e) Z. S. Wu, W. C. Ren, L. B. Gao, J. P. Zhao, Z. P. Chen, B. L. Liu, D. M. Tang, B. Yu, C. B. Jiang, H. M. Cheng, ACS Nano 3 (2009) 411.

[6] (a) A. O'Hare, F. V. Kusmartsev, K. I. Kugel, Nano Lett. 12 (2012) 1045. (b) A. Kara, H. Enriquez, A. P. Seitsonen, L.C. Lew Yan Voon, S. Vizzini, B. Aufray, H. Oughaddou, Surf. Sci. Rep. 67 (2012) 1. (c) J. Deepthi, D. Ayan, Acc. Chem. Res. 47 (2014) 593.

[7] (a) N. J. Roome, J. D. Carey, ACS Appl. Mater. Inter. 6 (2014), 7743-7750. (b) L. Li, S. Lu, J. Pan, Z. Qin, Y. Wang, Y. Wang, G. Cao, S. Du, H. Gao, Adv. Mater. 26 (2014) 4820.

[8] S. Nigam, S. Gupta, D. Banyai, R. Pandey, C. Majumder, Phys. Chem. Chem. Phys. 17 (2015) 6705

[9] (a) A. Favron, E. Gaufres, F. Fossard, A. L. Phaneuf-L'Heureux, N. Y. W. Tang, P. L. Levesque, A. Loiseau, R. Leonelli, S. Francoeur, R. Martel, Nat. Mater. 14 (2015) 826. (b) Y. Cai, G. Zhang, Y. Zhang, J. Phys. Chem. C 119 (2015), 13929.

[10] (a) A. Splendiani, L. Sun, Y. Zhang, T. Li, J. Kim, C.-Y. Chim, G. Galli, F. Wang, Nano Lett. 10 (2010) 1271. (b) J. N. Coleman, M. Lotya, A. O’Neill, S. D. Bergin, P. J. King, U. Khan, K. Young, A. Gaucher, S. De, R. J. Smith, I. V. Shvets, S. K. Arora, G. Stanton, H.-Y. Kim, K. Lee, G. T. Kim, G. S. Duesberg, T. Hallam, J. J. Boland, J. J. Wang, J. F. Donegan, J. C. Grunlan, G. Moriarty, A. Shmeliov, R. J. Nicholls, J. M. Perkins, E. M. Grieveson, K. Theuwissen, D. W. McComb, P. D. Nellist, V. Nicolosi, Science 331 (2011) 568. (c) H. S. Lee, S.-W. Min, M. K. Park, Y. T. Lee, P. J. Jeon, J. H. Kim, S. Ryu, S. Im, Small 8 (2012) 3111. (d) Z. Zeng, Z. Yin, X. Huang, H. Li, Q. He, G. Lu, F. Boey, H. Zhang, Angew. Chem. Int. Ed. 50 (2011) 11093. 
[11] (a) T. Sasaki, M. Watanabe, H. Hashizume, H. Yamada, H. Nakazawa, J. Am. Chem. Soc. 118 (1996) 8329. (b) N. Sakai, Y. Ebina, K. Takada, T. Sasaki, J. Am. Chem. Soc. 126 (2004) 5851. (c) M. Muramatsu, K. Akatsuka, Y. Ebina, K. Wang, T. Sasaki, T. Ishida, K. Miyake, M.-a. Haga, Langmuir 21 (2005) 6590. (d) B.-W. Li, M. Osada, T. C. Ozawa, Y. Ebina, K. Akatsuka, R. Ma, H. Funakubo, T. Sasaki, ACS Nano 4 (2010) 6673.

[12] (a) R. Ma, Z. Liu, L. Li, N. Iyi, T. Sasaki, J. Mater. Chem. 16 (2006) 3809. (b) R. Ma, Z. Liu, K. Takada, N. Iyi, Y. Bando, T. Sasaki, J. Am. Chem. Soc. 129 (2007) 5257. (c) S. Ida, D. Shiga, M. Koinuma, Y. Matsumoto, J. Am. Chem. Soc. 130 (2008) 14038. (d) D. Yan, J. Lu, M. Wei, J. Han, J. Ma, F. Li, D. G. Evans, X. Duan, Angew. Chem. Int. Ed. 48 (2009) 3073. (e) D. Yan, J. Lu, J. Ma, M. Wei, D. G. Evans, X. Duan, Angew. Chem. Int. Ed. 50 (2011) 720.

[13] (a) D. Golberg, Y. Bando, Y. Huang, T. Terao, M. Mitome, C. Tang, C. Zhi, ACS Nano 4 (2010) 2979. (b) A. L. Gibb, N. Alem, J. Chen, K. J. Erickson, J. Ciston, A. Gautam, M. Linck, A. Zettl, J. Am. Chem. Soc. 135 (2013) 6758. (C) T. Sainsbury, A. Satti, P. May, Z. Wang, I. McGovern, Y. K. Gunko, J. Coleman, J. Am. Chem. Soc. 134 (2012) 18758. (d) W. Lei, D. Portehault, D. Liu, S. Qin, Y. Chen, Nature Commun. 4 (2013) 1777. (e) K. Uosaki, G. Elumalai, H. Noguchi, T. Masuda, A. Lyalin, A. Nakayama, T. Taketsugu, J. Am. Chem. Soc. 136 (2014) 6542.

[14] (a) R. Ras, Y. Umemura, C. Johnston, A. Yamagishi, R. Schoonheydt, Phys. Chem. Chem. Phys. 9 (2007) 918. (b) K. Takagi, T. Shichi, J. Photochem. Photobiol. C 1 (2000) 113. (c) S. Takagi, T. Shimada, Y. Ishida, T. Fujimura, D. Masui, H. Tachibana, M. Eguchi, H. Inoue, Langmuir 29 (2013) 2108 (d) T. Tsukamoto, T. Shimada, S. Takagi, J. Phys. Chem. A 117 (2013) 7823.

[15] J. Sakamoto, J. van Heijst, O. Lukin, A. D. Schlüter, Angew. Chem. Int. Ed. 48 (2009) 1030.

[16] H. Furukawa, U. Mueller, O. M. Yaghi, Angew. Chem. Int. Ed. 54 (2015) 3417.

[17] H.-C. J. Zhou, S. Kitagawa, Chem. Soc. Rev. 43 (2014) 5415. 
[18] (a) A. Dmitriev, H. Spillmann, N. Lin, J. V. Barth, K. Kern, Angew. Chem. Int. Ed. 42 (2003) 2670. (b) A. P. Seitsonen, M. Lingenfelder, H. Spillmann, A. Dmitriev, S. Stepanow, N. Lin, K. Kern, J. V. Barth, J. Am. Chem. Soc. 128 (2006) 5634. (c) S. Stepanow, M. Lingenfelder, A. Dmitriev, H. Spillmann, E. Delvigne, N. Lin, X. Deng, C. Cai, J. V. Barth, K. Kern, Nat. Mater. 3 (2004) 229. (d) H. Spillmann, A. Dmitriev, N. Lin, P. Messina, J. V. Barth, K. Kern, J. Am. Chem. Soc. 125 (2003) 10725. (e) M. A. Lingenfelder, H. Spillmann, A. Dmitriev, S. Stepanow, N. Lin, J. V. Barth, K. Kern, Chem. Eur. J. 10 (2004) 1913. (f) N. Lin, S. Stepanow, F. Vidal, J. V. Barth, K. Kern, Chem. Commun. (2005) 1681. (g) T. Classen, M. Lingenfelder, Y. Wang, R. Chopra, C. Virojanadara, U. Starke, G. Costantini, G. Fratesi, S. Fabris, S. de Gironcoli, S. Baroni, S. Haq, R. Raval, K. Kern, The J. Phys. Chem. A 111 (2007) 12589. (h) S. L. Tait, Y. Wang, G. Costantini, N. Lin, A. Baraldi, F. Esch, L. Petaccia, S. Lizzit, K. Kern, J. Am. Chem. Soc. 130 (2008) 2108.

[19] (a) S. Stepanow, N. Lin, D. Payer, U. Schlickum, F. Klappenberger, G. Zoppellaro, M. Ruben, H. Brune, J. V. Barth, K. Kern, Angew. Chem. Int. Ed. 46 (2007) 710. (b) U. Schlickum, R. Decker, F. Klappenberger, G. Zoppellaro, S. Klyatskaya, M. Ruben, I. Silanes, A. Arnau, K. Kern, H. Brune, J. V. Barth, Nano Lett. 7 (2007) 3813. (c) G. Pawin, K. L. Wong, D. Kim, D. Sun, L. Bartels, S. Hong, T. S. Rahman, R. Carp, M. Marsella, Angew. Chem. Int. Ed. 47 (2008) 8442. (d) T. Sirtl, S. Schlögl, A. Rastgoo-Lahrood, J. Jelic, S. Neogi, M. Schmittel, W. M. Heckl, K. Reuter, M. Lackinger, J. Am. Chem. Soc. 135 (2013) 691.

[20] H. Walch, J. Dienstmaier, G. Eder, R. Gutzler, S. Schlögl, T. Sirtl, K. Das, M. Schmittel, M. Lackinger, J. Am. Chem. Soc. 133 (2011) 7909.

[21] Y. Li, J. Xiao, T. E. Shubina, M. Chen, Z. Shi, M. Schmid, H.-P. Steinrück, J. M. Gottfried, N. Lin, J. Am. Chem. Soc 134 (2012) 6401.

[22] (a) N. Varaksa, L. Pospíśil, T. F. Magnera, J. Michl, Proc. Natl. Acad. Sci. U. S. A. 99 (2002) 5012. (b) J. Michl, T. F. Magnera, Proc. Natl. Acad. Sci. U. S. A. 99 (2002) 4788. 
[23] (a) R. Makiura, S. Motoyama, Y. Umemura, H. Yamanaka, O. Sakata, H. Kitagawa, Nat. Mater. 9 (2010) 565. (b) S. Motoyama, R. Makiura, O. Sakata, H. Kitagawa, J. Am. Chem. Soc. 133 (2011) 5640. (c) R. Makiura, R. Usui, Y. Sakai, A. Nomoto, A. Ogawa, O. Sakata, A. Fujiwara, ChemPlusChem 79 (2014) 1352.

[24] (a) P. Amo-Ochoa, L. Welte, R. Gonzalez-Prieto, P. J. Sanz Miguel, C. J. Gomez-Garcia, E. Mateo-Marti, S. Delgado, J. Gomez-Herrero, F. Zamora, Chem. Commun. 46 (2010) 3262. (b) P.-Z. Li, Y. Maeda, Q. Xu, Chem. Commun. 47 (2011) 8436. (c) J.-C. Tan, P. J. Saines, E. G. Bithell, A. K. Cheetham, ACS Nano 6 (2012) 615. (d) G. Xu, T. Yamada, K. Otsubo, S. Sakaida, H. Kitagawa, J. Am. Chem. Soc. 134 (2012) 16524.

[25] (a) H. K. Arslan, O. Shekhah, J. Wohlgemuth, M. Franzreb, R. A. Fischer, C. Woell, Adv. Funct. Mater. 21 (2011) 4228. (b) A. Dragaesser, O. Shekhah, O. Zybaylo, C. Shen, M. Buck, C. Woell, D. Schlettwein, Chem. Commun. 48 (2012) 663. (c) Z.-G. Gu, J. Buerck, A. Bihlmeier, J. Liu, O. Shekhah, P. G. Weidler, C. Azucena, Z. Wang, S. Heissler, H. Gliemann, W. Klopper, A. S. Ulrich, C. Woell, Chem. Eur. J. 20 (2014) 9879. (d) W. Guo, J. Liu, P. G. Weidler, J. Liu, T. Neumann, D. Danilov, W. Wenzel, C. Feldmann, C. Woell, Phys. Chem. Chem. Phys. 16 (2014) 17918. (e) M. Hanke, H. K. Arslan, S. Bauer, O. Zybaylo, C. Christophis, H. Gliemann, A. Rosenhahn, C. Woell, Langmuir 28 (2012) 6877. (f) L. Heinke, M. Cakici, M. Dommaschk, S. Grosjean, R. Herges, S. Braese, C. Woell, ACS Nano 8 (2014) 1463. (g) L. Heinke, C. Woell, Phys. Chem. Chem. Phys. 15 (2013) 9295. (h) B. Liu, M. Ma, D. Zacher, A. Betard, K. Yusenko, N. Metzler-Nolte, C. Woll, R. A. Fischer, J. Am. Chem. Soc. 133 (2011) 1734. (i) B. Liu, O. Shekhah, H. K. Arslan, J. Liu, C. Woell, R. A. Fischer, Angew. Chem., Int. Ed. 51 (2012) 807. (j) B. Liu, M. Tu, D. Zacher, R. A. Fischer, Adv. Funct. Mater. 23 (2013) 3790. (k) J. Liu, E. Redel, S. Walheim, Z. Wang, V. Oberst, J. Liu, S. Heissler, A. Welle, M. Moosmann, T. Scherer, M. Bruns, H. Gliemann, C. Woell, Chem. Mater. 27 (2015) 1991. (1) J. Liu, T. Waechter, A. Irmler, P. G. Weidler, H. Gliemann, F. Pauly, V. Mugnaini, M. Zharnikov, C. Woell, ACS Appl. Mater. Interfaces 7 
(2015) 9824. (m) J. Liu, B. Lukose, O. Shekhah, H. K. Arslan, P. Weidler, H. Gliemann, S. Brase, S. Grosjean, A. Godt, X. Feng, K. Muellen, I.-B. Magdau, T. Heine, C. Woell, Sci. Rep. 2 (2012) 925. (n) E. Redel, Z. Wang, S. Walheim, J. Liu, H. Gliemann, C. Woell, Appl. Phys. Lett. 103 (2013) 091903. (o) P. St. Petkov, G. N. Vayssilov, J. Liu, O. Shekhah, Y. Wang, C. Woell, T. Heine, ChemPhysChem 13 (2012) 2025. (p) M. Tsotsalas, J. Liu, B. Tettmann, S. Grosjean, A. Shahnas, Z. Wang, C. Azucena, M. Addicoat, T. Heine, J. Lahann, J. Overhage, S. Braese, H. Gliemann, C. Woell, J. Am. Chem. Soc. 136 (2014) 8. (q) M. Tu, S. Wannapaiboon, R. A. Fischer, Dalton Trans. 42 (2013) 16029. (r) Z. Wang, J. Liu, H. K. Arslan, S. Grosjean, T. Hagendorn, H. Gliemann, S. Braese, C. Woell, Langmuir 29 (2013) 15958. (s) Z. Wang, J. Liu, B. Lukose, Z. Gu, P. G. Weidler, H. Gliemann, T. Heine, C. Woell, Nano Lett. 14 (2014) 1526. (t) J.-L. Zhuang, D. Ar, X.-J. Yu, J.X. Liu, A. Terfort, Adv. Mater. 25 (2013) 4631. (u) J.-L. Zhuang, D. Ceglarek, S. Pethuraj, A. Terfort, Adv. Funct. Mater. 21 (2011) 1442. (v) J.-L. Zhuang, M. Kind, C. M. Grytz, F. Farr, M. Diefenbach, S. Tussupbayev, M. C. Holthausen, A. Terfort, J. Am. Chem. Soc. 137 (2015) 8237.

[26] (a) T. Bauer, Z. Zheng, A. Renn, R. Enning, A. Stemmer, J. Sakamoto, A. D. Schlüter, Angew. Chem. Int. Ed. 50 (2011) 7879. (b) Z. Zheng, C. S. Ruiz-Vargas, T. Bauer, A. Rossi, P. Payamyar, A. Schütz, A. Stemmer, J. Sakamoto, A. D. Schlüter, Macromol. Rapid Commun. 34 (2013) 1670. (c) Z. Zheng, L. Opilik, F. Schiffmann, W. Liu, G. Bergamini, P. Ceroni, L.-T. Lee, A. Schütz, J. Sakamoto, R. Zenobi, J. VandeVondele, A. D. Schlüter, J. Am. Chem. Soc. 136 (2014) 6103.

[27] (a) E. Breuning, M. Ruben, J.-M. Lehn, F. Renz, Y. Garcia, V. Ksenofontov, P. Gütlich, E. Wegelius, K. Rissanen, Angew. Chem. Int. Ed. 39 (2000) 2504. (b) M. Ruben, E. Breuning, J.-P. Gisselbrecht, J.-M. Lehn, Angew. Chem. Int. Ed. 39 (2000) 4139. (c) U. Ziener, J.-M. Lehn, A. Mourran, M. Möller, Chem. Eur. J. 8 (2002) 951.

[28] (a) F. S. Han, M. Higuchi, D. G. Kurth, J. Am. Chem. Soc. 130 (2008) 2073. (b) C.-W. Hu, T. Sato, J. Zhang, S. Moriyama, M. Higuchi, J. Mater. Chem. C 1 (2013) 3408. (c) T. Kurita, Y. 
Nishimori, F. Toshimitsu, S. Muratsugu, S. Kume, H. Nishihara, J. Am. Chem. Soc. 132 (2010) 4524. (d) Y. Yamanoi, J. Sendo, T. Kobayashi, H. Maeda, Y. Yabusaki, M. Miyachi, R. Sakamoto, H. Nishihara, J. Am. Chem. Soc. 134 (2012) 20433. (e) R. Sakamoto, S. Katagiri, H. Maeda, H. Nishihara, Coord. Chem. Rev. 257 (2013) 1493. (f) R. Sakamoto, S. Katagiri, H. Maeda, Y. Nishimori, S. Miyashita, H. Nishihara, J. Am. Chem. Soc. 137 (2015) 734. (g) R. Sakamoto, K.-H. Wu, R. Matsuoka, H. Maeda, H. Nishihara, Chem. Soc. Rev. 2015, doi:10.1039/C5CS00081E.

[29] (a) T. Kambe, R. Sakamoto, K. Hoshiko, K. Takada, M. Miyachi, J.-H. Ryu, S. Sasaki, J. Kim, K. Nakazato, M. Takata, H. Nishihara, J. Am. Chem. Soc. 135 (2013) 2462. (b) K. Hoshiko, T. Kambe, R. Sakamoto, K. Takada, H. Nishihara, Chem. Lett. 43 (2014) 252. (c) T. Kambe, R. Sakamoto, T. Kusamoto, T. Pal, N. Fukui, K. Hoshiko, T. Shimojima, Z. Wang, T. Hirahara, K. Ishizaka, S. Hasegawa, F. Liu, H. Nishihara, J. Am. Chem. Soc. 136 (2014) 14357. (d) T. Kambe, T. Kusamoto, R. Sakamoto, H. Nishihara, Macromol. Symp. 351 (2015) 78. (e) T. Pal, M. L. Foo, T. Kusamoto, R. Matsuoka, R. Sakamoto, H. Nishihara, ChemPlusChem, 2015, 80, 1255.

[30] (a) R. Sakamoto, K. Hoshiko, Q. Liu, T. Yagi, T. Nagayama, S. Kusaka, M. Tsuchiya, Y. Kitagawa, W.-Y. Wong, H. Nishihara, Nat. Commun. 6 (2015) 6713. (b) R. Sakamoto, T. Iwashima, M. Tsuchiya, R. Toyoda, R. Matsuoka, J. F. Kogel, S. Kusaka, K. Hoshiko, T. Yagi, T. Nagayama, H. Nishihara, J. Mater. Chem. A. 3 (2015) 15357.

[31] K. Takada, R. Sakamoto, S.-T. Yi, S. Katagiri, T. Kambe, H. Nishihara, J. Am. Chem. Soc. 137 (2015) 4681.

[32] (a) P. Cassoux, Coord. Chem. Rev. 185-186 (1999) 213. (b) R. Kato, Chem. Rev. 104 (2004) 5319.

[33] (a) H. Nishihara, M. Okuno, N. Kogawa, K. Aramaki, J. Chem. Soc. (1998) 2651. (b) Y. Shibata, B.-H. Zhu, S. Kume, H. Nishihara, Dalton Trans. (2009) 1939. (c) T. Kambe, S. Tsukada, R. Sakamoto, H. Nishihara, Inorg. Chem. 50 (2011) 6856. (d) R. Sakamoto, S. Tsukada, H. Nishihara, Dalton Trans. 41 (2012) 10123. 
[34] Z. F. Wang, N. Su, F. Liu, Nano Lett. 13 (2013) 2842.

[35] (a) I. V. Sazanovich, C. Kirmaier, E. Hindin, L. Yu, D. F. Bocian, J. S. Lindsey, D. Holten, J. Am. Chem. Soc. 126 (2004) 2664. (b) M. A. Filatov, A. Y. Lebedev, S. N. Mukhin, S. A. Vinogradov, A. V. Cheprakov, J. Am. Chem. Soc. 132 (2010) 9552. (c) S. Kusaka, R. Sakamoto, Y. Kitagawa, M. Okumura, H. Nishihara, Chem. Asian J. 7 (2012) 907. (d) S. Kusaka, R. Sakamoto, H. Nishihara, Inorg. Chem. 53 (2014) 3275. (e) M. Tsuchiya, R. Sakamoto, S. Kusaka, Y. Kitagawa, M. Okumura, H. Nishihara, Chem. Commun. 50 (2014) 5881.

[36] (a) S. A. Baudron, Dalton Trans. 42 (2013) 7498. (b) H. Maeda, M. Hasegawa, T. Hashimoto, T. Kakimoto, S. Nishio, T. Nakanishi, J. Am. Chem. Soc. 128 (2006) 10024. (c) R. Matsuoka, R. Toyoda, R. Sakamoto, M. Tsuchiya, K. Hoshiko, T. Nagayama, Y. Nonoguchi, K. Sugimoto, E. Nishibori, T. Kawai, H. Nishihara, Chem. Sci. 6 (2015) 2853. 